\title{
Acute and Chronic Effects of Clothianidin, Thiamethoxam and Methomyl on Chironomus dilutus
}

\author{
Bryn M. Phillips ${ }^{1}$ D $\cdot$ Jennifer P. Voorhees ${ }^{1} \cdot$ Katie Siegler $^{1} \cdot$ Laura McCalla $^{1} \cdot$ Peter Meertens $^{2} \cdot$ Julie Bower $^{1}$. \\ Ron S. Tjeerdema ${ }^{1}$
}

Received: 3 August 2021 / Accepted: 12 November 2021 / Published online: 7 December 2021

(c) The Author(s) 2021

\begin{abstract}
Organism tolerance thresholds for emerging contaminants are vital to the development of water quality criteria. Acute (96h) and chronic (10-day) effects thresholds for neonicotinoid pesticides clothianidin and thiamethoxam, and the carbamate pesticide methomyl were developed for the midge Chironomus dilutus to support criteria development using the UC Davis Method. Median lethal concentrations (LC50s) were calculated for acute and chronic exposures, and the $25 \%$ inhibition concentrations (IC25) were calculated for the chronic exposures based on confirmed chemical concentrations. Clothianidin effect concentrations were $4.89 \mu \mathrm{g} / \mathrm{L}, 2.11 \mu \mathrm{g} / \mathrm{L}$ and $1.15 \mu \mathrm{g} / \mathrm{L}$ for $96-\mathrm{h} \mathrm{LC} 50,10$-day LC50 and 10-day IC25, respectively. Similarly, thiamethoxam concentrations were $56.4 \mu \mathrm{g} / \mathrm{L}, 32.3 \mu \mathrm{g} / \mathrm{L}$ and $19.6 \mu \mathrm{g} / \mathrm{L}$, and methomyl concentrations were $244 \mu \mathrm{g} / \mathrm{L}, 266 \mu \mathrm{g} / \mathrm{L}$ and $92.1 \mu \mathrm{g} / \mathrm{L}$. Neonicotinoid effect concentrations compared favorably to previously published 96-h and 14-day LC50 concentrations, and methomyl effect concentrations were within the acute survival range reported for Chironomus species and other organisms.
\end{abstract}

Keywords Clothianidin $\cdot$ Thiamethoxam $\cdot$ Methomyl $\cdot$ Neonicotinoid $\cdot$ Carbamate

Organism tolerance thresholds for emerging contaminants are vital to the development of water quality criteria. A national water quality criteria methodology was established by the U.S. EPA in 1985 (U.S. EPA 1985), but newer methods have added valuable procedures for developing criteria (TenBrook et al. 2009). More recently, University of California Davis and California's Central Valley Regional Water Quality Control Board developed a method for the derivation of aquatic life pesticide water quality criteria that utilizes features from previous methodologies to "generate the most flexible and robust criteria" (TenBrook et al. 2010). The development of the University of California Davis Method (UCDM) was the second part of a larger project that also

Bryn M. Phillips

bmphillips@ucdavis.edu

1 Marine Pollution Studies Laboratory, Department of Environmental Toxicology, University of California Davis, 34500 Highway One, Monterey, CA 93940, USA

2 Central Coast Regional Water Quality Control Board, 895 Aerovista Place, Suite 101, San Luis Obispo, CA 93401-7906, USA included use of the method to derive criteria for pesticides of concern.

Criteria derivation requires appropriate, high quality ecotoxicological effects data from taxonomically diverse groups of organisms (TenBrook et al. 2010). The UCDM provides a list of data requirements, including physical-chemical data, ecotoxicological data and human health action levels. Data needs in the ecotoxicological category include acute and chronic laboratory exposures with aquatic insects. Acute exposures are defined as lasting up to $96 \mathrm{~h}$ with a survival endpoint, whereas chronic exposures include a portion of the organism life cycle and include endpoints such as growth or reproduction.

Three insecticides were chosen based on their levels of concern in California (USA) receiving waters. California Department of Pesticide Regulation currently prioritizes imidacloprid and methomyl for monitoring in waterways receiving agricultural inputs, and recommend clothianidin be included in future monitoring efforts (Main 2019). These insecticides are frequently detected in agricultural watersheds at concentrations exceeding U.S. Environmental Protection Agency (U.S. EPA) aquatic life benchmark values, 
and are known to cause toxicity to laboratory test organisms (Anderson et al. 2018; Starner and Goh 2012).

The objectives of this study were to not only develop thresholds that could contribute to the development of UCDM criteria, but to provide toxicity threshold values that could be used to interpret ongoing monitoring data. The concentrations of detected insecticides in receiving waters can be compared to LC50 values to determine the contributions of those chemicals to the observed toxicity.

\section{Methods}

All tests were conducted at the University of California, Davis Marine Pollution Studies Laboratory (MPSL). Methods for the acute toxicity test followed U.S. EPA (2002), and methods for the chronic test follow USGS (Ingersoll et al. 2013; Kunz et al. 2017). Rangefinder tests were conducted for each test duration and insecticide. Rangefinder tests consisted of a broad range of concentrations assured to cause mortality on the high end, and were based, in part, on existing published thresholds for Chironomus and similar species. The clothianidin and thiamethoxam rangefinder tests were conducted with nominal concentrations ranging between 1 and $200 \mu \mathrm{g} / \mathrm{L}$. The methomyl rangefinder test was conducted with nominal concentrations ranging up to $5000 \mu \mathrm{g} / \mathrm{L}$. Rangefinder tests were followed with two definitive tests for each test duration and chemical.

Test solutions were prepared by diluting $10 \mathrm{mg}$ pure standard reference materials (Accustandard, New Haven, $\mathrm{CT}$ ) in one $\mathrm{mL}$ acetone. This solution was added to a oneliter volumetric flask of distilled water, and test concentrations were prepared through further dilution using volumetric flasks and MPSL well water. Toxicity tests consisted of four replicate $300-\mathrm{mL}$ glass beakers for each chemical concentration and four beakers for the negative control consisting of MPSL well water. Approximately $5 \mathrm{~mL}$ of clean sand was added to each test container as a substrate for the organisms. Twelve organisms were added to each beaker. Beakers were arranged randomly, and each received $200 \mathrm{~mL}$ of test solution. Tests were conducted at $23^{\circ} \mathrm{C}$ and a photoperiod of $16 \mathrm{~h}$ light: $8 \mathrm{~h}$ dark.

Egg cases were purchased from Aquatic Bio Systems (Fort Collins, CO), and were ordered to arrive eight to ten days prior to test initiation. Larvae were hatched and acclimated to test temperature and conductivity. Larvae were between second and third instar at test initiation with at least $50 \%$ of larvae at third instar, approximately 7 days post hatch. Upon arrival, egg cases were placed in a $250-\mathrm{mL}$ crystalizing dish containing MPSL well water at a temperature that varied by no more than $3^{\circ} \mathrm{C}$ from transport conditions. At the first sign of hatching, egg cases were carefully transferred to a culture dish prepared with well water and clean sand, and provided aeration. Every $24 \mathrm{~h}$ egg cases were transferred into a newly prepared dish until sufficient larvae were acquired, or until the egg cases were spent. Cultures were fed daily and overlying water was renewed every other day. Larval health was monitored daily by observing appearance. If more than $5 \%$ of the larvae appear unhealthy during the $48 \mathrm{~h}$ prior to the test, the test was rescheduled. Larvae were individually placed into test containers using a clean transfer pipette. Only animals that were healthy and had built tubes were used in the test batch.

Temperature, dissolved oxygen, $\mathrm{pH}$, ammonia, and conductivity were measured at test initiation and termination. Hardness and alkalinity were measured at the beginning of the test. Initial test solutions were sampled at the time of solution preparation. Test solutions were renewed by slowly pouring half of the solution from the container, taking care not to remove or disturb any organisms, and reserving a portion for water quality measurements. Fresh tests solutions were introduced by gently pouring down the side of the beaker to minimize turbulence and stress to the organisms. Water quality was measured on old and new solutions at the time of renewal, and included dissolved oxygen on new samples, and $\mathrm{DO}, \mathrm{pH}$, and conductivity on old samples.

Acute test replicates were fed $0.5 \mathrm{~mL} 4 \mathrm{~g} / \mathrm{L}$ Tetramin ${ }^{\circledR}$ slurry daily, and chronic tests were fed based on test day $\left(0.5 \mathrm{~mL}\right.$ Tetramin ${ }^{\circledR}$ slurry for the first 4 days, $1.0 \mathrm{~mL}$ on days $5-7$, and $1.5 \mathrm{~mL}$ on days $8-10$ ). Food was thoroughly mixed before aliquots were taken, and care was taken to prevent formation of fungal matting on the surface of the sand as that can be a sign of overfeeding.

Tests were terminated by sieving organisms from the sand at the bottom of the exposure chambers. The contents of the beaker were poured through a $500 \mu \mathrm{m}$ screen, and water was gently sprayed on the sand to expose the surviving larvae in their tubes. Surviving larvae generally had a rich red color and were active, whereas dead larvae had lost their color. In addition to color, larvae that were not moving were assessed under a dissecting microscope to determine mortality. Missing larvae were considered dead. Larvae were counted and discarded for acute tests, but were weighed for chronic tests by thoroughly rinsing and transferring them to a pre-ashed foil packet. Packets were first dried overnight at $60^{\circ} \mathrm{C}$, cooled in a desiccator for one hour, and weighed to the nearest $0.0001 \mathrm{~g}$. Packets were then placed into crucibles and ashed in a muffle furnace at $550^{\circ} \mathrm{C}$ for $2 \mathrm{~h}$, cooled in the desiccator, and reweighed to the nearest $0.0001 \mathrm{~g}$.

All chemical concentrations from the definitive tests were extracted using U.S. EPA method 3510C, and measured using U.S. EPA method 8321. Reporting limits for clothianidin, thiamethoxam and methomyl were $0.4 \mu \mathrm{g} / \mathrm{L}$, $1.0 \mu \mathrm{g} / \mathrm{L}$ and $0.1 \mu \mathrm{g} / \mathrm{L}$, respectively. Statistical calculations of rangefinder tests were based on nominal concentrations, and calculations from definitive tests were based on 
confirmed chemical concentrations using Comprehensive Environmental Toxicology Information System ${ }^{\mathrm{TM}}$ (CETIS) software (McKinleyville, CA). Median-lethal concentrations (LC50s) were calculated for 96-h and 10-day survival using trimmed Spearman-Karber analysis, and 25\% inhibition concentrations (IC25s) were calculated for 10-day growth using linear interpolation. No observed and lowest observed effect concentrations (NOECs and LOECs) were calculated for all endpoints using analysis of variance (ANOVA) with Dunnett's tests $(\alpha=0.05)$. Maximum acceptable toxicant concentration (MATC), a primary component of the UCDM, was calculated from NOEC and LOEC values.

\section{Results and Discussion}

All 96-h and 10-day tests were paired and initiated at the same time. All toxicity tests met test acceptability criteria of $>90 \%$ survival in the control with the exception of the first thiamethoxam 96-h test. These results led to conducting a third thiamethoxam definitive test. Most water quality results were within acceptable ranges for the test organism: $\mathrm{pH}-6.99-9.58$, conductivity $-554-1240 \mu \mathrm{S} / \mathrm{cm}$, temperature $-22.1-24.0^{\circ} \mathrm{C}$, hardness $-128-238 \mathrm{mg} / \mathrm{L} \mathrm{CaCO}_{3}$ and alkalinity $78-163 \mathrm{mg} / \mathrm{L} \mathrm{CaCO}_{3}$. Some dissolved oxygen concentrations in the latter portions of the 10-day tests dropped below the recommended $2.5 \mathrm{mg} / \mathrm{L}$ threshold (range - 1.04-9.78 mg/L). Low oxygen concentrations occurred in higher pesticide concentrations with zero survival, and were likely the byproduct of surplus food. Reference toxicant tests with potassium chloride were conducted concurrently with definitive tests. Median lethal concentrations from all reference toxicant tests ranged from 3.99 to $6.07 \mathrm{mg} / \mathrm{L}$.
Measured concentrations of clothianidin ranged from $27 \%$ to $52 \%$ of nominal concentrations. The low recovery of clothianidin in the experimental samples was reflected in the percent recovery of the analytical laboratory control spikes, which ranged from $40.8 \%$ to $51 \%$. The UCDM prefers measured concentrations to be within $20 \%$ of nominal concentrations. Because analytical laboratory control spike recoveries were less than the recovery limit of $70 \%$, and because measured treatment concentrations of clothianidin were so low, final concentrations were corrected by taking the mean between the measured and nominal concentrations (Raby et al. 2018). Thiamethoxam recoveries were higher and ranged from $62 \%$ to $105 \%$ of nominal concentrations. Percent recovery of the analytical laboratory control spikes ranged from $72.3 \%$ to $95.3 \%$ (recovery limit $=70 \%$ ). Measured concentrations of methomyl ranged from $60 \%$ to $76 \%$ of nominal concentrations, and were also corrected as described above. Percent recovery of the analytical laboratory control spikes ranged from $67.5 \%$ to $77.9 \%$ (recovery limit $=23 \%$ ). Surrogate recoveries of tributylphosphate in the analyses of all three insecticides ranged from $61.3 \%$ to $119 \%$, with an acceptable range of $36 \%$ to $140 \%$. No insecticides were detected in the method blanks.

Statistical analysis of the clothianidin rangefinder test data produced a $96-\mathrm{h} \mathrm{LC50} \mathrm{of} 13.9 \mu \mathrm{g} / \mathrm{L}$, and a 10-day LC50 of $4.45 \mu \mathrm{g} / \mathrm{L}$ (Table 1). Based on these results, definitive tests were conducted with the following concentrations: 1, 2, 5, 10, 25 and $50 \mu \mathrm{g} / \mathrm{L}$. Based on corrected clothianidin concentrations, two acute tests produced LC50 values of 8.82 and $7.64 \mu \mathrm{g} / \mathrm{L}$. Corresponding chronic tests produced LC50 values of 3.54 and $3.46 \mu \mathrm{g} / \mathrm{L}$, and IC25 values of 1.86 and $1.93 \mu \mathrm{g} / \mathrm{L}$.

Table 1 Summary of statistical results for individual clothianidin tests: point estimates and NOEC/LOEC/MATC based on nominal (rangefinder) and corrected (definitive) concentrations

\begin{tabular}{|c|c|c|c|c|c|c|c|c|c|}
\hline $\begin{array}{l}\text { Clothianidin } \\
\text { point esti- } \\
\text { mates }\end{array}$ & $\begin{array}{l}\text { 96-Hour } \\
\text { LC50 }(\mu \mathrm{g} / \mathrm{L})\end{array}$ & $95 \%$ LCL & $95 \%$ UCL & $\begin{array}{l}\text { 10-Day } \\
\text { LC50 }(\mu \mathrm{g} / \mathrm{L})\end{array}$ & $95 \% \mathrm{LCL}$ & $95 \%$ UCL & $\begin{array}{l}\text { 10-Day IC25 } \\
(\mu \mathrm{g} / \mathrm{L})\end{array}$ & $95 \%$ LCL & $95 \% \mathrm{UCL}$ \\
\hline Rangefinder & 13.9 & 11.9 & 16.3 & 4.85 & 4.1 & 5.72 & 1.64 & NA & 1.69 \\
\hline Definitive 1 & 8.82 & 7.82 & 9.94 & 3.51 & 3.09 & 3.98 & 1.86 & 1.51 & 2.03 \\
\hline Definitive 2 & 7.64 & 6.64 & 8.79 & 3.46 & 3.06 & 3.91 & 1.93 & NA & NA \\
\hline \multirow{2}{*}{$\begin{array}{l}\text { Clothianidin } \\
\text { comparison }\end{array}$} & \multicolumn{3}{|l|}{ 96-h survival } & \multicolumn{3}{|c|}{ 10-day survival } & \multicolumn{3}{|c|}{ 10-day growth } \\
\hline & $\operatorname{NOEC}(\mu \mathrm{g} / \mathrm{L})$ & LOEC $(\mu \mathrm{g} / \mathrm{L})$ & $\begin{array}{l}\text { MATC } \\
(\mu \mathrm{g} / \mathrm{L})\end{array}$ & $\begin{array}{l}\text { NOEC } \\
(\mu \mathrm{g} / \mathrm{L})\end{array}$ & $\begin{array}{l}\mathrm{LOEC} \\
(\mu \mathrm{g} / \mathrm{L})\end{array}$ & $\begin{array}{l}\text { MATC } \\
(\mu \mathrm{g} / \mathrm{L})\end{array}$ & $\begin{array}{l}\text { NOEC } \\
(\mu \mathrm{g} / \mathrm{L})\end{array}$ & $\begin{array}{l}\mathrm{LOEC} \\
(\mu \mathrm{g} / \mathrm{L})\end{array}$ & $\begin{array}{l}\text { MATC } \\
(\mu \mathrm{g} / \mathrm{L})\end{array}$ \\
\hline Rangefinder & 5 & 10 & 7.07 & 1 & 5 & 2.24 & 1 & 5 & 2.24 \\
\hline$\%$ Control & $100 \%$ & $68 \%$ & & $100 \%$ & $64 \%$ & & $99 \%$ & $4 \%$ & \\
\hline Definitive 1 & 7.55 & 17.2 & 11.4 & 1.50 & 3.80 & 2.39 & 1.50 & 3.80 & 2.39 \\
\hline$\%$ Control & $65 \%$ & $4 \%$ & & $100 \%$ & $49 \%$ & & $112 \%$ & $5 \%$ & \\
\hline Definitive 2 & 3.40 & 6.95 & 4.86 & 1.37 & 3.40 & 2.16 & 3.40 & $>3.40$ & NA \\
\hline$\%$ Control & $100 \%$ & $60 \%$ & & $98 \%$ & $59 \%$ & & $42 \%$ & NA & \\
\hline
\end{tabular}


The UCDM utilizes acute LC50 values for criteria development, but because NOEC/LOEC data are the most widely available for chronic tests, the UCDM utilizes the MATC (TenBrook et al. 2010). The actual no effect concentration would lie between the NOEC and LOEC, therefore the MATC, which is the geometric mean of the NOEC and LOEC, is considered a reasonable estimate. Definitive MATC values were 11.4 and $4.86 \mu \mathrm{g} / \mathrm{L}$ for the $96-\mathrm{h}$ survival endpoint, and 2.39 and $2.16 \mu \mathrm{g} / \mathrm{L}$ for the 10-day survival endpoint. A chronic MATC value $(2.39 \mu \mathrm{g} / \mathrm{L})$ could only be calculated for the 10-day growth endpoint of the first definitive test.
Rangefinder data analyses produced a thiamethoxam 96-h LC50 of $61.2 \mu \mathrm{g} / \mathrm{L}$, and a 10 -day LC50 of $50.9 \mu \mathrm{g} / \mathrm{L}$ (Table 2). Based on these results, definitive tests were conducted with concentration ranges similar to those of the rangefinder: $10,25,50,100$ and $200 \mu \mathrm{g} / \mathrm{L}$. Based on measured thiamethoxam concentrations, two acute tests produced LC50 values of 54.3 and $58.5 \mu \mathrm{g} / \mathrm{L}$. Three chronic tests produced LC50 values of $34.7,31.8$ and $30.3 \mu \mathrm{g} / \mathrm{L}$, and IC25 values of $23.8,17.8$ and $17.3 \mu \mathrm{g} / \mathrm{L}$. MATC values for the three endpoints of the first definitive test were $29.7 \mu \mathrm{g} / \mathrm{L}$. MATC values for the second definitive test were $50.6 \mu \mathrm{g} / \mathrm{L}$ for the 96-h survival endpoint, and $22.6 \mu \mathrm{g} / \mathrm{L}$ for the 10-day endpoints.

Table 2 Summary of statistical results for individual thiamethoxam tests: point estimates and NOEC/LOEC/MATC based on nominal (rangefinder) and measured (definitive) concentrations

\begin{tabular}{|c|c|c|c|c|c|c|c|c|c|}
\hline $\begin{array}{l}\text { Thiameth- } \\
\text { oxam point } \\
\text { estimates }\end{array}$ & $\begin{array}{l}\text { 96-Hour } \\
\text { LC50 }(\mu \mathrm{g} / \mathrm{L})\end{array}$ & $95 \%$ LCL & $95 \%$ UCL & $\begin{array}{l}\text { 10-Day } \\
\text { LC50 }(\mu \mathrm{g} / \mathrm{L})\end{array}$ & $95 \% \mathrm{LCL}$ & $95 \%$ UCL & $\begin{array}{l}\text { 10-Day IC2 } \\
(\mu \mathrm{g} / \mathrm{L})\end{array}$ & $2595 \% \mathrm{LCL}$ & $95 \%$ UCL \\
\hline Rangefinder & 61.2 & 55.9 & 66.9 & 50.9 & 45.4 & 56.9 & 28.7 & NA & 30.7 \\
\hline Definitive 1 & 54.3 & 49.1 & 60.1 & 31.8 & 28.2 & 35.9 & 17.8 & 12.2 & 20.1 \\
\hline Definitive 2 & 58.5 & 49.3 & 69.4 & 30.3 & 29.1 & 31.7 & 17.3 & 4.2 & 29.6 \\
\hline \multirow{2}{*}{$\begin{array}{l}\text { Thiameth- } \\
\text { oxam com- } \\
\text { parison }\end{array}$} & \multicolumn{3}{|l|}{ 96-h survival } & \multicolumn{3}{|c|}{ 10-day survival } & \multicolumn{3}{|l|}{ 10-day growth } \\
\hline & $\begin{array}{l}\text { NOEC } \\
(\mu \mathrm{g} / \mathrm{L})\end{array}$ & $\begin{array}{l}\mathrm{LOEC} \\
(\mu \mathrm{g} / \mathrm{L})\end{array}$ & $\begin{array}{l}\text { MATC } \\
(\mu \mathrm{g} / \mathrm{L})\end{array}$ & $\begin{array}{l}\text { NOEC } \\
(\mu \mathrm{g} / \mathrm{L})\end{array}$ & $\begin{array}{l}\text { LOEC } \\
(\mu \mathrm{g} / \mathrm{L})\end{array}$ & $\begin{array}{l}\text { MATC } \\
(\mu \mathrm{g} / \mathrm{L})\end{array}$ & $\begin{array}{l}\text { NOEC } \\
(\mu \mathrm{g} / \mathrm{L})\end{array}$ & $\begin{array}{l}\text { LOEC } \\
(\mu \mathrm{g} / \mathrm{L})\end{array}$ & MATC $(\mu \mathrm{g} / \mathrm{L})$ \\
\hline Rangefinder & 50 & 100 & 70.7 & 25 & 50 & 35.4 & 25 & 50 & 35.4 \\
\hline$\%$ Control & $94 \%$ & $0 \%$ & & $98 \%$ & $53 \%$ & & $119 \%$ & $3 \%$ & \\
\hline Definitive 1 & 21 & 42 & 29.7 & 21 & 42 & 29.7 & 21 & 42 & 29.7 \\
\hline$\%$ Control & $94 \%$ & $85 \%$ & & $100 \%$ & $4 \%$ & & $81 \%$ & NA & \\
\hline Definitive 2 & 32 & 80 & 50.6 & 16 & 32 & 22.6 & 16 & 32 & 22.6 \\
\hline$\%$ Control & $84 \%$ & $29 \%$ & & $100 \%$ & $44 \%$ & & $108 \%$ & $5 \%$ & \\
\hline
\end{tabular}

Table 3 Summary of statistical results for individual methomyl tests: point estimates and NOEC/LOEC/MATC based on nominal (rangefinder) and corrected (definitive) concentrations

\begin{tabular}{|c|c|c|c|c|c|c|c|c|c|}
\hline $\begin{array}{l}\text { Methomyl } \\
\text { point esti- } \\
\text { mates }\end{array}$ & $\begin{array}{l}\text { 96-Hour } \\
\text { LC50 ( } \mu \mathrm{g} / \mathrm{L})\end{array}$ & $95 \%$ LCL & $95 \%$ UCL & $\begin{array}{l}\text { 10-Day } \\
\text { LC50 }(\mu \mathrm{g} / \mathrm{L})\end{array}$ & $95 \%$ LCL & $95 \%$ UCL & $\begin{array}{l}\text { 10-Day IC25 } \\
(\mu \mathrm{g} / \mathrm{L})\end{array}$ & $95 \%$ LCL & $95 \% \mathrm{UCL}$ \\
\hline Rangefinder & 242 & 213 & 274 & 254 & 221 & 290 & 9.07 & NA & 238 \\
\hline Definitive 1 & 319 & 287 & 355 & 356 & 329 & 386 & 163 & 15.1 & 324 \\
\hline Definitive 2 & 280 & 252 & 312 & 297 & 270 & 327 & 58.5 & 32.7 & 133 \\
\hline \multirow{2}{*}{$\begin{array}{l}\text { Methomyl } \\
\text { comparison }\end{array}$} & \multicolumn{3}{|l|}{ 96-h survival } & \multicolumn{3}{|c|}{ 10-day survival } & \multicolumn{3}{|c|}{ 10-day growth } \\
\hline & $\begin{array}{l}\text { NOEC } \\
(\mu \mathrm{g} / \mathrm{L})\end{array}$ & $\begin{array}{l}\text { LOEC } \\
(\mu \mathrm{g} / \mathrm{L})\end{array}$ & $\begin{array}{l}\text { MATC } \\
(\mu \mathrm{g} / \mathrm{L})\end{array}$ & $\begin{array}{l}\text { NOEC } \\
(\mu \mathrm{g} / \mathrm{L})\end{array}$ & $\begin{array}{l}\text { LOEC } \\
(\mu \mathrm{g} / \mathrm{L})\end{array}$ & $\begin{array}{l}\text { MATC } \\
(\mu \mathrm{g} / \mathrm{L})\end{array}$ & $\begin{array}{l}\text { NOEC } \\
(\mu \mathrm{g} / \mathrm{L})\end{array}$ & $\begin{array}{l}\text { LOEC } \\
(\mu \mathrm{g} / \mathrm{L})\end{array}$ & $\begin{array}{l}\text { MATC } \\
(\mu \mathrm{g} / \mathrm{L})\end{array}$ \\
\hline Rangefinder & 100 & 500 & 224 & 100 & 500 & 224 & 100 & 500 & 224 \\
\hline$\%$ Control & $96 \%$ & $13 \%$ & & $98 \%$ & $15 \%$ & & $91 \%$ & $3 \%$ & \\
\hline Definitive 1 & 220 & 435 & 309 & 220 & 435 & 309 & 435 & $>435$ & NA \\
\hline$\%$ Control & $90 \%$ & $18 \%$ & & $100 \%$ & $20 \%$ & & $13 \%$ & NA & \\
\hline Definitive 2 & 205 & 400 & 286 & 205 & 400 & 286 & 205 & 400 & 286 \\
\hline$\%$ Control & $88 \%$ & $11 \%$ & & $94 \%$ & $15 \%$ & & $35 \%$ & $6 \%$ & \\
\hline
\end{tabular}


Statistical analysis of the methomyl rangefinder test data produced a 96-h LC50 of $242 \mu \mathrm{g} / \mathrm{L}$, and a 10-day LC50 of $254 \mu \mathrm{g} / \mathrm{L}$ (Table 3). Based on these results, definitive tests were conducted with lower concentration ranges: 50, 100, 250, 500 and $1000 \mu \mathrm{g} / \mathrm{L}$. Based on corrected methomyl concentrations, two acute tests produced LC50 values of 319 and $280 \mu \mathrm{g} / \mathrm{L}$. Chronic tests produced LC50 values of 356 and $297 \mu \mathrm{g} / \mathrm{L}$, and IC25 values of 163 and $58.5 \mu \mathrm{g} / \mathrm{L}$. The IC25 values are based on replicate data that were quite variable, and in the case of the first definitive test, had an interrupted dose response. MATC values for the survival endpoints of the first definitive test were $309 \mu \mathrm{g} / \mathrm{L}$ (MATC for growth could not be calculated). MATC values all endpoints of the second definitive test were $286 \mu \mathrm{g} / \mathrm{L}$.

The neonicotinoid effect concentrations developed in this study compared favorably to previously published 96-h and 14-day LC50 concentrations. Recently developed acute LC50 values for clothianidin and thiamethoxam, calculated from recovery-corrected measured concentrations, ranged from 5.93 to $11.6 \mu \mathrm{g} / \mathrm{L}$ and from 55.3 to $61.9 \mu \mathrm{g} / \mathrm{L}$, respectively (Maloney et al. 2017; Raby et al. 2018). Although some published methomyl effect concentrations were somewhat dated and mostly based on nominal concentrations, LC50s generated in the current study were within the reported range for some invertebrates, but were lower than those previously reported for Chironomus. Acute 96-h LC50s ranged from 47 to $760 \mu \mathrm{g} / \mathrm{L}$ for Gammarus italicus, Daphnia longispina and Gammarus pulex (Aboul-Ela and Khalil 1987; Pantani et al. 1997), and the acute 48-h LC50 for Chironomus was reported at $1000 \mu \mathrm{g} / \mathrm{L}$ by Norland et al. (1974).

In addition to supporting the development of water quality criteria, effects concentrations produced in this study will also be used to evaluate monitoring data, particularly in California programs such as the Department of Pesticide Regulation (CDPR) Surface Water Monitoring Program (Main 2019), and the State Water Resources Control Boards Surface Water Ambient Monitoring Program (https://www.waterboards.ca.gov/water_issues/programs/ swamp/). Well-developed threshold concentrations can provide insight into the causes of toxicity in laboratory tests, and direct water quality managers in their decision making, particularly in support of Total Maximum Daily Loads (Central Coast Regional Water Quality Control Board 2014), and the implementation of best management practices as outlined in the current central California coastal agricultural order (Central Coast Regional Water Quality Control Board 2021). Approximately half of the clothianidin and thiamethoxam concentrations detected in SWAMP samples between 2018 and 2020 exceeded the 96-h LC50s reported in this study.
Funding Funding for this project was provided by the Central Coast Regional Water Quality Control Board through the Avila Beach Water Quality Restoration Fund.

\section{Declarations}

Conflict of interest The authors have no conflicts of interest to declare that are relevant to the content of this article.

Open Access This article is licensed under a Creative Commons Attribution 4.0 International License, which permits use, sharing, adaptation, distribution and reproduction in any medium or format, as long as you give appropriate credit to the original author(s) and the source, provide a link to the Creative Commons licence, and indicate if changes were made. The images or other third party material in this article are included in the article's Creative Commons licence, unless indicated otherwise in a credit line to the material. If material is not included in the article's Creative Commons licence and your intended use is not permitted by statutory regulation or exceeds the permitted use, you will need to obtain permission directly from the copyright holder. To view a copy of this licence, visit http://creativecommons.org/licenses/by/4.0/.

\section{References}

Aboul-Ela IA, Khalil MT (1987) The acute toxicity of three pesticides on organisms of different trophic levels as parameters of pollution in lake Wadi El Rayan. El Fayoum, Egypt. Proc Zool Soc UAR 13:31-36

Anderson BS, Phillips BM, Voorhees JP et al (2018) Changing patterns in toxicity associated with current use pesticides in agriculture runoff in California. Integr Environ Assess Manag 14:270-281. https://doi.org/10.1002/ieam.2005

Central Coast Regional Water Quality Control Board (2014) Adopting total maximum daily loads for toxicity and pesticides in Santa Maria River Watershed. California Environmental Protection Agency and California Regional Water Quality Control Board Central Coast Region. Staff Report for Regular Meeting of January 30, 2014

Central Coast Regional Water Quality Control Board (2021) Proposed general waste discharge requirements for discharges from irrigated lands. Order No. R3-2021-0040. State of California Central Coast Regional Water Quality Control Board

Ingersoll C, Little E, Kunz J, et al (2013) Chronic toxicity of Azoxystrobin in water-only toxicity tests with select freshwater invertebrates. Study Outline for the Toxicology Branch of the Columbia Environmental Research Center (CERC). USGS, Columbia MO

Kunz J, Ingersoll C, Smalling K, Elskus A, Kuivila K (2017) Chronic toxicity of azoxystrobin to freshwater amphipods, midges, cladocerans and mussels in water-only exposures. Environ Toxicol Chem 36:2308-2315. https://doi.org/10.1002/etc.3764

Main A (2019) Study 321. Surface Water Monitoring for Pesticides in Agricultural Areas in the Central Coast and Southern California, 2019. In: Regulation CDoP (ed.) California Department of Pesticide Regulation, Sacramento, CA

Maloney EM, Morrissey CA, Headley JV, Peru KM, Liber K (2017) Cumulative toxicity of neonicotinoid insecticide mixtures to Chironomus dilutus under acute exposure scenarios. Environ Toxicol Chem 36:3091-3101. https://doi.org/10.1002/etc.3878

Norland RL, Mulla MS, Pelsue FW, Ikeshoji T (1974) Conventional and new insecticides for the control of chironomid midges. Proc Pap Annu Conf Calif Mosq Contr Assoc 42:181-183 
Pantani C, Pannunzio G, De Cristofaro M, Novelli AA, Salvatori M (1997) Comparative acute toxicity of some pesticides, metals, and surfactants to Gammarus italicus Goedm. and Echinogammarus tibaldii Pink. and stock (Crustacea: Amphipoda). Bull Environ Contam Toxicol 59:963-967

Raby M, Nowierski M, Perlov D et al (2018) Acute toxicity of 6 neonicotinoid insecticides to freshwater invertebrates. Environ Toxicol Chem 37:1430-1445. https://doi.org/10.1002/etc.4088

Starner K, Goh KS (2012) Detections of the neonicotinoid insecticide imidacloprid in surface waters of three agricultural regions of California, USA, 2010-2011. Bull Environ Contam Toxicol 88(3):316-321. https://doi.org/10.1007/s00128-011-0515-5

TenBrook PL, Tjeerdema RS, Hann P, Karkoski J (2009) Methods for deriving pesticide aquatic life criteria. Rev Environ Contam Toxicol 199:19-109

TenBrook PL, Fojut TL, Hann P, Karkoski J, Tjeerdema RS (2010) The University of California-Davis methodology for deriving aquatic life pesticide water quality criteria. Rev Environ Contam Toxicol 209:1-155. https://doi.org/10.1007/978-1-4419-6883-8_1

U.S. EPA (2002) Methods for measuring acute toxicity of effluents and receiving water to freshwater and marine organisms. EPA821-R-02-012. Office of Research and Development, Washington, DC

U.S. EPA (1985) Guidelines for deriving numerical national water quality criteria for the protection of aquatic organisms and their uses, PB-85-227049. Stephan CE, Mount DI, Hansen DJ, Gentile JH, Chapman GA, Brungs WA, editors. Office of Research and Development, Duluth, MN

Publisher's Note Springer Nature remains neutral with regard to jurisdictional claims in published maps and institutional affiliations. 